\title{
PRINCIPLES OF FOSTERING SCIENTIFIC LANGUAGE OF PHYSICS BY MOUNTAINOUS HIGH SCHOOL STUDENTS
}

\author{
Diep Ngoc Le $e^{1,+}$, \\ Tra Huong Do ${ }^{2}$
}

\section{Article History}

Received: 19 September 2020

Accepted: 15 October 2020

Published: 30 December 2020

\section{Keywords}

Language of Physics, scientific language, fostering language, high school

\author{
${ }^{1}$ Tay Bac University, Vietnam; \\ ${ }^{2}$ Hanoi National University of Education, Vietnam \\ ${ }^{+}$Corresponding author • Email: lediep@utb.edu.vn
}

\section{INTRODUCTION}

In Vietnam, we have found very few studies on language of Physics. There have been some studies in teaching Physics in high school, but these researches did not study deeply into the language of Physics. Some authors have considered training students in the language of Physics as part of the measures to help foster and develop other competencies such as problem-solving competence or experimental competence... Typical is 'Training language to help students master physics experiments and common arguments in Physics' is one of the measures to foster problem-solving competence (Pham Thi Ngoc Thang, 2003); Thuy's thesis applied the LAMAP teaching process of Tra (2013) to help students promote problem-solving competence for students via the cognitive activities of thermological knowledge - Grade 8. One of the conclusions is' $90 \%$ of teachers commented that through the activities, students have acquired knowledge and developed written and spoken language' (Nguyen Thi Thuy, 2018); however, Thuy did not analyze carefully the opportunities and results of fostering language for students.

What are the principles of fostering the language of Physics in teaching Vietnamese mountainous students? In the next part of the article, we present the principles and illustrative examples in teaching Physics in high school.

\section{LITERATURE REVIEW}

\subsection{Scientific language}

"Words are amongst the tools of the job in the research institute and the classroom as people work towards new thoughts, but how exactly do they act on human minds? How have they done so in the growth of scientific ideas?" (Sutton, 1992). His book stressed the centrality of language in scientific thinking and gave a new meaning to what it means to be 'doing science'. Then, educational researchers have confirmed the important role of language in science. Montgomery (2003) stated "As a shared form of knowledge, scientific understanding is inseparable from the written and spoken word. There are no boundaries, no walls between the doing of science and the communication of it; communicating is the doing of science" (cited Evagorou \& Osborne, 2010). Language functions play a central role in science as a key cognitive tool for developing higher-order thinking and problem-solving abilities that, in turn, support academic literacy in all subject areas.

Research-based science curriculum for grades K-8 of FOSS (Full Option Science System) in University of California, Berkeley, in which language functions (reading, writing, speaking, listening) have also been confirmed as a key cognitive tool for developing higher-order thinking and problem-solving abilities that, in turn, support academic literacy in all subject areas (FOSSweb, 2002). Language functions are the purpose for which speech or writing is used and involve both vocabulary and grammatical structure. Understanding and using language functions 
appropriately is important in effective communication. Students use numerous language functions in all disciplines to mediate communication and facilitate thinking.

In many ways, learning science like learning a new language and the vocabulary of science does pose problems for learners. There are words simply a name of a real object or entity like 'clock', but the concept 'acceleration' which does not refer to an object or an entity, is somehow derived from 'velocity' and experience - the observation that 'when a ball is rolling down ramps then the velocity of the ball is changed' and 'defining acceleration as the rate of change of velocity'.

Wellington \& Osborne (2001) showed a classification or "taxonomy" of the words of science.

\begin{tabular}{|c|c|}
\hline & Description \\
\hline $\begin{array}{l}\text { Level 1: Naming words } \\
\text { 1.1. Familiar objects, new names (synonyms). } \\
\text { 1.2. New objects, new name } \\
\text { 1.3. Names of chemical elements } \\
\text { 1.4. Other nomenclature }\end{array}$ & $\begin{array}{l}\text { These are words that denote identifiable, observable, } \\
\text { real objects or entities: 'pollen', 'saliva'... Many of } \\
\text { these are simply synonyms for everyday words already } \\
\text { familiar to pupils, like 'spit, or 'push'... }\end{array}$ \\
\hline $\begin{array}{l}\text { Level 2: Process words } \\
\text { 2.1. Capable of ostensive definition, i.e. being shown. } \\
\text { 2.2. Not capable of ostensive definition. }\end{array}$ & $\begin{array}{l}\text { These are words that denote processes that happen in } \\
\text { science: 'evaporation', 'condensation', 'fusion', } \\
\text { 'vaporization', 'combustion', and 'evolution'. }\end{array}$ \\
\hline $\begin{array}{l}\text { Level 3: Concept words } \\
\text { 3.1. Derived from experience (sensory concepts). } \\
\text { 3.2. With dual meanings, i.e. everyday and scientific: } \\
\text { for example, 'work'. } \\
\text { 3.3. Theoretical constructs (total abstractions, } \\
\text { idealizations, and postulated entities). }\end{array}$ & $\begin{array}{l}\text { The third, and largest, category of science words are } \\
\text { concept words. These are words that denote concepts of } \\
\text { various types: 'work', 'energy', 'power, 'force', } \\
\text { 'volume', 'temperature'... }\end{array}$ \\
\hline Level 4: Mathematical 'words' and symbols & $\begin{array}{l}\text { The language of mathematics, its "words" and } \\
\text { "symbols", can be places at the fourth and highest level } \\
\text { of abstraction in a hierarchy of scientific words. The } \\
\text { mathematical language used in advanced physics is } \\
\text { neither derived from, nor directly applicable to, } \\
\text { experience. }\end{array}$ \\
\hline
\end{tabular}

\subsection{Language of Physics}

The language of Physics which is a type of scientific language, was formed and associated with the development of Physics. It helps scientists describe and practice science and also helps to transmit scientific information. In Physics learning, Osborne (1996) said that learning Physics was 'more akin to the learning of a foreign language than it is to the learning of historical facts' (cited Henderson \& Wellington, 1998) and this is also true of other sciences. In Physics teaching, Clive Sutton (1996) wrote 'the learner's experience of language as an interpretive system, actively used for generating new understanding, and of language as a labeling system for transmitting established information' and any forms of language convey meaning in different ways - they all have their importance and their limitations. The onus on the good teacher is to employ these forms appropriately, i.e. in the right place at the right time for learning science subjects is more effective and enjoyable (Wellington \& Osborne, 2001).

However, for vocabulary in Physics, Brookes (2006) stated three issues about students' difficulties in learning Physics: (1) meeting too many metaphors at the same time; (2) the wrong classification of concepts into the ontological category affected the students' reasoning process; (3) groping for the correct ontology to express students' scientific ideas. The analysis of Brookes (2006) was also consistent with the earlier Jerry Wellington's conclusions that learning 'concept words' in science was surely one where most learning difficulties are encountered because levels of abstraction and denoting ideas of 'concept words' were ascended. Further, these words often could not be understood as isolation (Wellington \& Osborne, 2001). For example, students can understand power before that they have to understand other words such as work and energy. Students need to learn motion, mass, velocity, mechanical work, energy before learning kinetic energy. "Concept words are part of the network of other words, all related together, often in a 'vertical' structure, i.e. the understanding of one word depends on prior understandings of other words. Without prior understandings, the structure collapses" (Wellington \& Osborne, 2001). The extension of 'concept words' such as fuel may be a name for petrol or paraffin, but gradually it acquires as 'a flammable material 
yielding energy' - general conceptual meaning, or lexical discontinuity such as in referring to '... resistor of a metal conductor increases', here have ignored the cause is the complex process when the vibration amplitudes of the atoms in the metal increase and the probability of collisions of electrons with atoms, other electrons, or impurities in the metal also increases...

Besides, mathematical 'words' and symbols are the highest level of abstraction in a hierarchy of scientific words (Wellington \& Osborne, 2001), so connecting and using mathematical 'words' and symbols in Physics is also a students' difficulties in learning Physics. The use of Maths to describe the physical world seem to take naturally and comfortably with a few students but the opposite many struggle with it. Redish \& Kuo (2015) wrote: "Although the formal mathematical syntax may be the same across the disciplines of mathematics and physics, the uses and meanings of that formal syntax may differ dramatically between the two disciplines. These differences in semantic meaning may be masked by the apparent similarity in the formal syntax". During the learning process, the students not only use Maths in doing Physics, they also use Physics in doing Maths.

About the link between the ontology of Physics with Mathematics, Collins (2004) proposed the model Ontology "Layer-cake" (Figure 1). The conceptual layers and their relationships are illustrated in hierarchical descriptions in this Physics-based models. The physical concept layer is used to represent the physical attributes of the physical object. Following, the mathematical expression layer represents the formalized statements of the physical concepts, i.e., the laws of physics in symbolic mathematical form, such as the symbol of 'force' is $\overrightarrow{\mathrm{F}}$, the causal relationship between 'acceleration', 'force' and 'mass' in mathematical expression of the second Newton' law: $\vec{a}=\frac{\vec{F}}{m}$. Mathematical expressions have been resulting from physical models, and they are complete safe for a solution. But for many reasons, mathematical expressions may be difficult to solve, so these approximations are often made by neglecting terms of it that are considered to have a small effect on solutions. To set an estimate of the answers then numerical, or discrete, approximation methods are resorted. This final interpolation layer of the model will provide the answers needed by other models.

In thinking about teaching mathematical physics, Redish \& Kuo (2015) showed four steps - modeling, processing, interpreting, and evaluating (Figure 2). Using this diagram helps teachers focus on teaching Physics more than just mathematical processing because their students

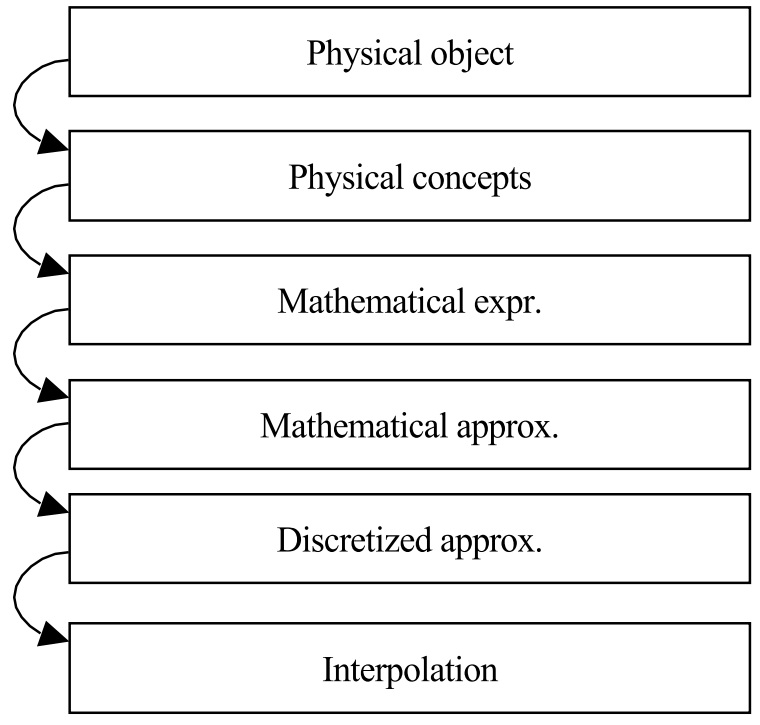

Figure 1. The model Ontology "Layer-cake"

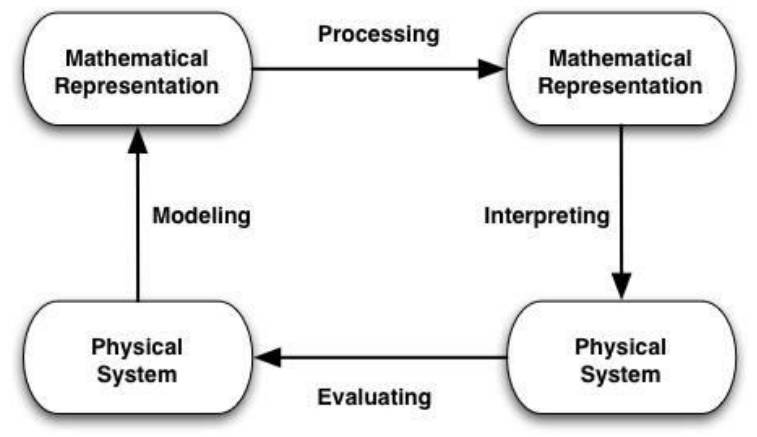

Figure 2. A model of mathematical modeling can often tend to solve mathematical expressions without seeing the physical meaning of them.

\section{RESEARCH METHODS AND RESULTS}

We introduce 4 principles of learning the language of physics-based on previous research on scientific language and scientific language fostering, considering the context of high school students in mountainous areas.

\subsection{Principle 1: Fostering language of Physics in the context of Physic learning}

At present, many educational researchers have considered science learning and language learning to be advantageous to both, and they need to be integrated. Language skills are developed by the learning and doing of science and vice versa, the thinking - learning - doing of science requires the use of language skills (Exploratorium, 2015a). The relationship between critical thinking skills of undergraduate students and voluntary reading has been 
researched by Hawkins (2012). The results showed that the ability to read and read well help student in using skills of critical thinking such as inductive reasoning, deductive reasoning, analysis, evaluation, and inference.

The public learning laboratory - Exploratorium in the US showed eight guiding principles for developing language in the context of science (Exploratorium, 2015a). In which stated, a multitude of affordances to use language in authentic and meaningful ways are provided by inquiry-based science although, language participation can be "flawed" (such as using symbols, diagrams, illustrating images, video clips,...) then still support language development. The practice of language skills in science is sophisticated, so the development of these language practices and skills needs teachers' supporting with questions, appropriate guidelines... To develop language skills in science classrooms, Gibbons (2002) proposed the mode continuum including 4 specific stages: (1) Experimenting (small groups); (2) Introducing key vocabulary (whole class); (3) Teacher-guided reporting (whole class); (4) Journal writing (individual)... to support students step by step (building scaffolding) to move from speaking to writing in science (Gibbons, 2002). The first step - 'Experimenting' is for a student to perform an experiment or to have a specific experience with science, from there, scientific vocabulary will appear and students will learn other language skills. The mode continuum has provided an authentic and meaningful context for students to develop the academic vocabulary of instruction.

In the context of physics learning, when students want to describe a phenomenon, they need specific terms of that phenomenon. For example, the description of a mechanical motion requires the terms of the trajectory (straight, curved, circular...), indicating how fast or slow the motion (velocity), indicating the change in velocity (acceleration), indicating location (coordinates); describing mechanical interactions between objects requires the term (force); stating the content of a law of physics requires two parts qualitative and quantitative (mathematical expressions)... In short, only when students are learning in the context of Physics, through solving physical problems, then they meet the physical terms, the physical concepts, physical representation... Thereby, they will be exercised of critical thinking in Physics and expressed of listening, speaking, reading, and writing in using language of Physics.

\subsection{Principle 2: Learning activities facilitate communication using the language of Physics}

Scientific language systems used in Physics and language skills are demonstrated in a classroom environment with communication activities. In that environment, teachers and students can communicate their ideas through different forms of communication with or without words. "Classroom conversations must create the conditions that will foster language development" (Gibbons, 2002).

For preschool children, to be able to learn a second language, the first principle to follow is "Children learn what they hear most". This principle was proposed based on research that infants can track speech sounds in foreign languages, and children's vocabulary size is important for language learning... (Konishi et al., 2014). However, for high school students, the learning process is always accompanied by classroom conversations. Swain (2000) argued that unlike what happens when a learner is reading, in a discussion, students have to speak in a way that makes it possible for others to understand their ideas which encourages them to process their language deeply sharper. Therefore, "science talk" is a tool that teachers can use in the teaching process to foster science language for students (Exploratorium, 2015a; Exploratorium, 2015b). During a conversation, students could share their observations, interpret evidence, and explain their findings. They support one another in making connections, refining ideas, and developing new perspectives. Thence, students could achieve understanding of the science individually and the student-to-student and student-to-teacher interactions also lead to the development of language.

This principle will be concretized in the following aspects, such as teaching the language of physics is not the purpose of providing "academic knowledge" but the purpose of training physical communication skills. Therefore, teachers' questions need to be clear and link with knowledge and skills to help produce words that need training because students express similar ideas in different ways.

For teaching strategies, language requirements need to be placed in the functional system of language (for example, put words in sentences, put sentences in paragraphs, paragraphs in text, clearly explain why). Teachers use different teaching methods and combine individual - group - collective forms, and learning tasks always create opportunities for students to discuss and communicate by language of Physics. In the course of active groups, "the teacher takes on the role of a facilitator, refocusing the group when necessary and encouraging a natural flow to the conversation where students respond to each other's ideas and no one person, including the teacher, dominates" (Exploratorium, 2015b). Further attention to the characteristics of ethnic minority students' communication skills 
gives appropriate instruction. Pham Song Ha (2012) showed that in communication, the best skills of Muong ethnic students are sensitive skills while the lowest is the ability to listen to objects.

\subsection{Principle 3. Paying attention to students' inherent ability to use scientific language, especially mountainous students}

Students' Vietnamese language, which is formed from many sources and associated with their living environment and communication, is not uniform in all students and complex right in itself. Research stated that ethnic students frequently use their mother tongue to communicate in life, so in learning when they have to use Vietnamese, students often encounter some errors in pronunciation, style, and context (Nguyen Van Gioi, 2011; Pham Song Ha, 2012). It not only has positive factors but also negative factors in the formation and use in communication. Gibbons (2002) stated "Explicit teaching is related to real-life use, so language understanding is developed in the context of actual language use". During a discussion, students are encouraged to use the language they have to express their ideas and they express similar ideas in different ways. If there are scientifically inaccurate ideas, they are dismissed in an open discussion or further investigation which relied on to help students find the correct conclusion and construct ideas then support them to progress in their scientific understanding. More specifically, in science, teachers used the daily experience of students, everyday language, or images, diagrams... help students envisage new ideas, e.g. the image about stone grinder envisages a solid cylinder (disk) to rotate around symmetry axis; an atom to the solar system is used to compare the structure of an atom; the flow of water in a pipe is placed next to the flow of an electric current in a conductor...

This principle is demonstrated by the following activities: Students of different language proficiencies are provided different scaffolds when they can participate in talks (e.g., teachers' questions vary from searching new words, to description, analyzing...; teachers' prompts are tailored to students' varying needs...); Using phenomena that students have experienced, or conducting for students to do experiments... are the ways providing frequent opportunities for talk within a science unit affords multiple meaningful contexts. Teachers use the available language of students and create opportunities to bridge from using everyday language to develop the language of science.

\subsection{Principle 4: Comparing and linking between talking and writing in using language of physics}

The public learning laboratory-exploratorium in the US stated two main measures for developing language in the context of science: Science talk and Science writing. In the science talk process, conclusions, theories, and new questions in thoughts are clarified; learners are exposed to new ideas and perspectives which encourage them to grow new understanding; using students' prior experiences in learning; students' ideas are acknowledged and they gradually take more responsibility for their learning; the collaborative nature of doing science will be taken through communication; students have opportunity to use their everyday language in the expression of personally scientific ideas (Exploratorium, 2015b).

"Science writing involves students in a metacognitive activity - they must consider the words they will use to communicate their thinking, reflecting and clarifying as they go" (Exploratorium, 2015c). Students' language and their scientific thinking are developed and refined in the writing process. Writing science is often especially difficult for mountainous students because they have to establish a bridge between describing phenomena in everyday language and the more formal, academic language associated with science content (Gibbons, 2002). Science writing and science talk have a strong reciprocal relationship together because "Talking can be a precursor to writing, and writing can be a precursor to talking" (Exploratorium, 2015a). Science talk provides the opportunity for students to listen to teachers or other students' opinions, which in turn helps them refine their ideas and language before writing. On the contrary, writing science first can help students to summarize their thoughts and arguments without worrying about missing ideas before speaking. Jimenez-Silva and Gomez (2011) used the mode continuum and researched six different experiments focusing on gravity which were conducted by students in a fourth to fifth-grade class. In this study, the experiment about Chaotic Pendulum was described specifically in the article.

To make scientific papers or speeches, students also need to search and research appropriate references. During the reading process, students evaluate and analyze documents so science writing and science talk not only assist students in learning knowledge but also to develop using students' scientific language. Karadeniz (2015) wrote "Reading is the most effective learning activity because learners can improve themselves regarding critical thinking, develop new and different perspectives, understand themselves and the world, and interpret events and situations they will face" (cited in Zubaidah et al., 2018). 
Teachers need to provide a framework to address different needs of students by using a hands-on, project approach to science learning; providing students with opportunities to listen, speak, read, and write; and providing an opportunity for students to work cooperatively to develop both social and academic language skills.

\subsection{Applying principles in planning lessons to foster language of Physics}

ELASTIC FORCE (GRADE 10 PHYSICS)

\section{Activity 1: Creating situations to learn elastic force}

\section{Purpose}

- Creating a physical learning context and being close to students through familiar pictures in life (applying principle 1);

- Help students to recall knowledge learned in middle school and the physics terms used in lessons;

- Teachers allow students to use everyday language in describing situations and experiments (applying principle 3).

\section{Content of learning activities}

\section{Step 1: Class discussion}

- Teachers use familiar pictures and tools in life and ask questions such as:

1) What is the name of the instrument in the picture?

2) When are the below tools often used?

3) Please tell us how to use this tool?

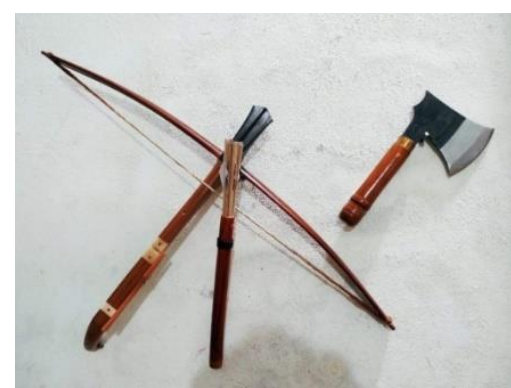

Crossbow

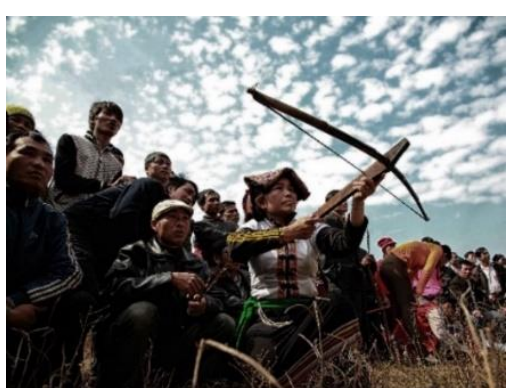

The archery competition (Source: http://danvan.vn/)

- Some students responded, others commented and added. At the same time, the teacher records the terms the students used (both from 'approximate' words). The teacher agrees with the students on the common terms of some words such as: pulling, compression $\rightarrow$ deformation; after stopping the applied force, objects that quickly regain their original shape $\rightarrow$ elastic.

- The teacher's small questions in communication with students can be:

+ For the arrow to shoot the furthest way, how should the shooter pull the bowstring?

+ How does it return original state after stretching or compression, or what is direction of the object's movement?

+ Teachers use tools that are familiar in students' lives to experiment with creating learning situations.

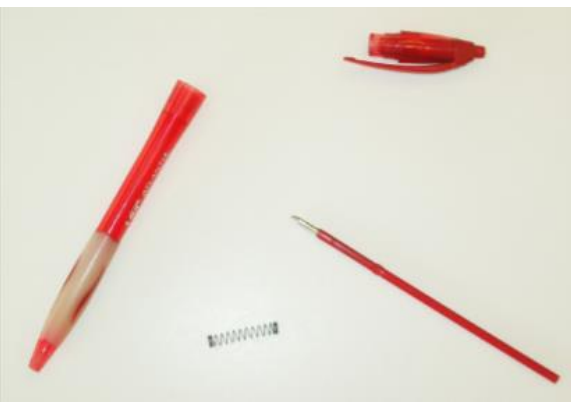

Why the ballpoint pens can press be?

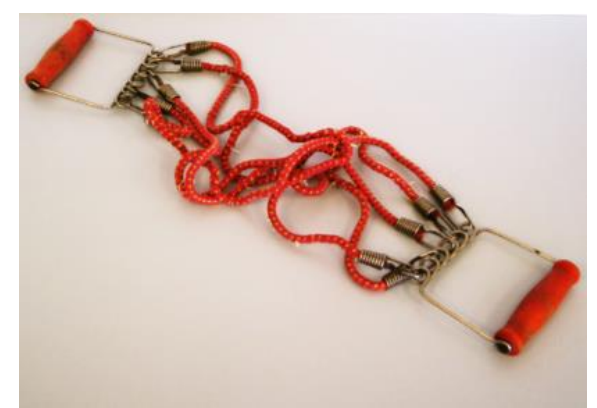

How does the shape of the rope change after pulling with your hand and when you stop pulling? 


\section{Step 2: Group activity}

- Teacher hand out experiment equipment to groups and ask students to take turns to hang two weights of different weights $\mathrm{m} 1$ and $\mathrm{m} 2$ into two identical springs with a fixed end.

Students perform experiments and turn to answer the questions:

1) Why does the object not fall?

2) What is the setpoint, direction, and direction of force to keep the object from falling?

3) What does the magnitude of the force that keeps the object from falling (elastic force) depend on?

- The answers are presented on an A3 sheet of paper, during which the teacher walks around the class to look at and through small group communication to edit the students' answers.

\section{Step 3: Teacher concludes and asks questions for the next activity}

- The teacher concludes about the physical terms used in the lesson and their meanings such as: elastic force, deformation, hardness, and at the same time explains non-technical phrases such as: proportional, contrariwise.

- Finally, the teacher asks the key question: What is a characteristic of the spring's elastic force?

\section{Product of activity}

Students report on group activity results (write their answers on paper).

- The spring's elastic force has kept the weight from falling

- According to the equilibrium condition of the point substance, the elastic force of the spring can be determined in this case with the point located at the object, the vertical direction, the upward direction.

- Force needed to extend or compress a spring by some distance scales with respect to that distance.

\section{Activity 2: Hooke's law}

\section{Purpose}

- Through the process of completing the learning task: students describe the characteristics of the spring's elastic force and the contents of Hooke's law.

- For language of Physics: In the process of discussion combining listening, speaking, reading, and Vietnamese, students learn knowledge, physics terms, and usage in the lesson.

\section{Content of learning activities}

\section{Step 1: Group activity}

- The teacher gives out work sheets to 4 groups (2 groups of A and 2 groups of B).

- During group activities, teachers will conduct quick questions and answers with students to orient and assist students in implementation methods, to correct understanding and correct use of physical terms.

(1) Tasks and materials for group A

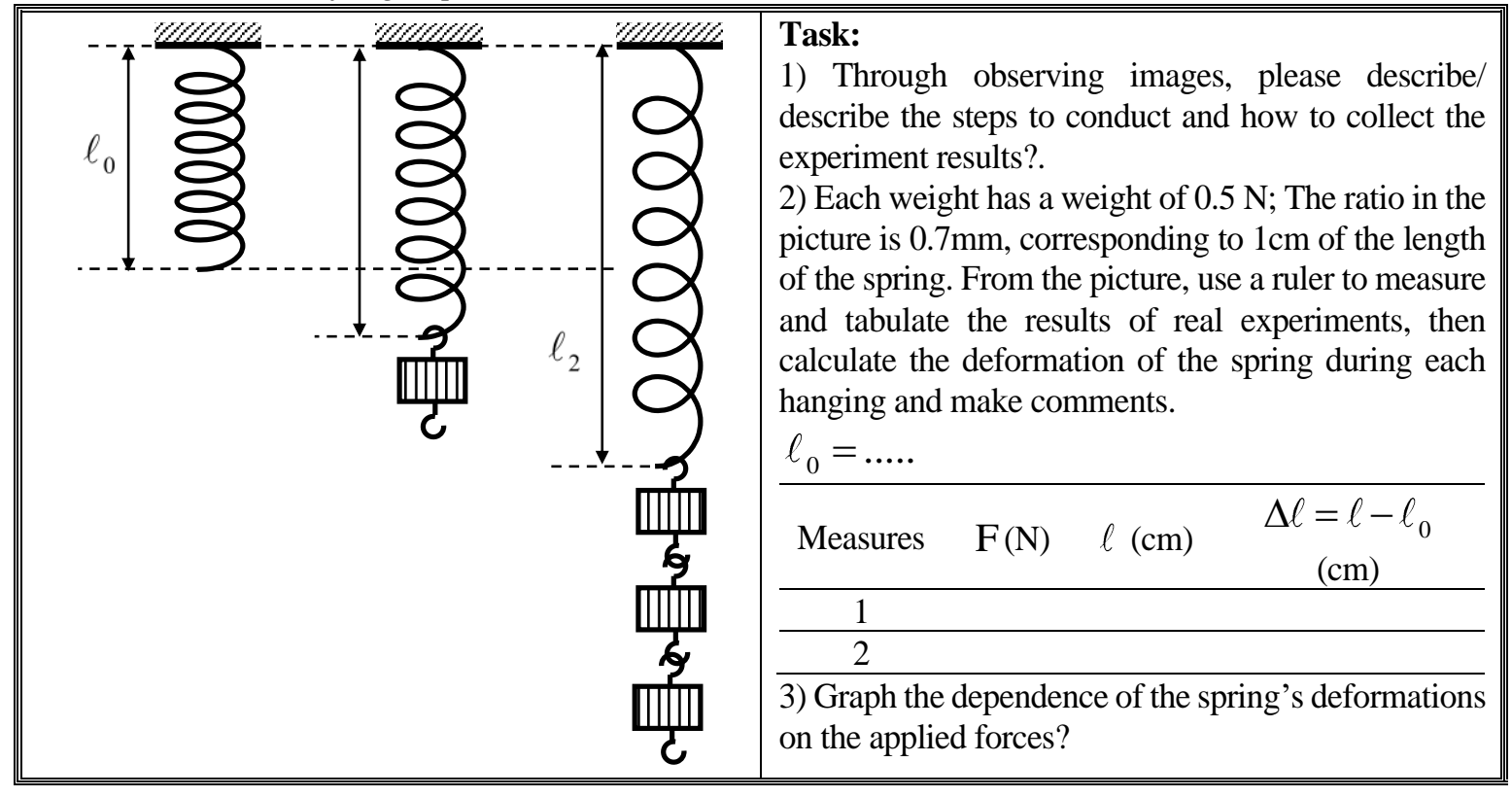


(2) Tasks and materials for group $B$

Experimental instruments include: a spring, a support, weights (each weighing $0.5 \mathrm{~N}$ ), a straight ruler is scaled divided to $\mathrm{mm}$.

Tasks: Conduct the experiment according to the following steps:

- Measure the length of the spring without hanging objects.

- Fixed 1 spring head (hanging on a support). Hanging on the other end of the spring in turn with different weights, respectively, in each suspension, the spring length is measured after stretching and looking for deformation of the spring.

- Record the experimental results in times and plot the dependence of the deformation of the spring on the applied force?

Step 2: Pair discussion (small group includes 1 student from group A and 1 student from group B), discuss and answer the questions in turn:

1) Please indicate the direction and the place of the spring's elastic force, draw an illustration.

2) What is the relationship between the elastic force and spring deformation (mathematical expression)? What is the significance of the difference between the ratio coefficients (group A and group B)?

3) What happens when too great a force is applied to the spring?

\section{Product of activity: The answers in small groups are written down on paper}

- The force $(F)$ needed to extend or compress a spring by some distance $(\Delta \ell)$ scales linearly concerning that distance - that is, $F=k .\left|\ell-\ell_{0}\right|=k .|\Delta \ell|$, where $\mathrm{k}$ is a constant factor characteristic of the spring (i.e., its stiffness), and $\Delta \ell=\left|\ell-\ell_{0}\right|$ is small compared to the total possible deformation of the spring; $\ell_{0}, \ell$ is the length of the spring when the object is not suspended and after the object is suspended.

- When the forces exceed some limit, spring is fail and cannot return to its original state anymore.

\section{Activity 3: Homework}

\section{Purpose}

- Students self-study, explore and expand the knowledge in lessons and application of lessons in life.

- Teachers allow students to complete tasks in many different forms of language (non-verbal or verbal), depending on the interests and abilities of each student. The tasks aim to practice reading and writing skills in physics.

\section{Content of learning activities}

Find an application of elastic force in life and re-describe its structure and operation by different forms: Hints: draw pictures / write lyrics / compose songs / diagrams... of an application used as: shock absorbers on motorbikes or cars...

\section{Product of activity}

- Content of individual students' notes (used in school records).

\section{DISCUSSION AND CONCLUSION}

Based on research in the field of language development in a science context, the language of Physics is one of scientific language. We have argued to offer a toolbox of four principles to promote learning mountains students' language of Physics and academic success. Four principles of language of physics development and example in planning lessons for teaching Physics offer implications for practice to promote learning knowledge and language of physic. Putting these principles into practice will contribute to increasing the scientific language competencies of mountainous students and will thus put them on the path to greater academic success and beyond. However, there is a need to continue research in pedagogical experiment to have quantitative assessments based on analysis of students' videos, tapes, and products to come up with specific measures for fostering students' language of physics; From there, the proposed principles will gradually go into teaching practice and contribute to improving the teaching quality of Physics in high schools for mountainous students. 


\section{REFERENCES}

Brookes, D. T. (2006). The role of language in learning Physics. Rutgers University, USA.

Collins, J. B. (2004). Standardizing an Ontology of Physics for Modeling and Simulation. Defense Technical Information Center, Fort Belvoir, VA.

Do Huong Tra (2013). LAMAP - a modern teaching method. University of Education Publishing House.

Evagorou, M. \& Osborne, J. (2010). The role of language in the learning and teaching of science. In J. Osborne \& J. Dillon (Eds.), Good practice in science teaching: what research has to say ( $2^{\text {nd }} \mathrm{ed}$.), New York: Open University Press/McGraw-Hill, 135-157.

Exploratorium (2015a). Developing Language in the Context of Science: A View from the Institute for Inquiry. The Institute for Inquiry, accessed from https://www.exploratorium.edu/education/ifi/inquiry-and-eld/educatorsguide/conceptual-overview

Exploratorium (2015b). Science Talk: A Tool for Learning Science and Developing Language. The Institute for Inquiry, accessed from https://www.exploratorium.edu/education/ifi/inquiry-and-eld/educators-guide/science-talk

Exploratorium (2015c). Science Writing: A Tool for Learning Science and Developing Language. The Institute for Inquiry, accessed from https://www.exploratorium.edu/education/ifi/inquiry-and-eld/educators-guide/science-writing

FOSSweb (2002). Science-Centered Language Development in Middle School. FOSS for Middle School, NSF Grant ESI-9553600, The Regents of the University of California.

Gibbons, P. (2002). Scaffolding language, scaffolding learning: Teaching second language learners in the mainstream classroom. Portsmouth, NH: Heinemann.

Hawkins, K. T. (2012). Thinking and reading among college undergraduates: An examination of the relationship between critical thinking skills and voluntary reading. Dissertation, University of Tennessee.

Henderson, J. \& Wellington, J. (1998). Lowering the language barrier in learning and teaching science. School Science Review, 79(288), 35-46.

Jimenez-Silva, M. \& Gomez, C. L. (2011). Developing Language Skills in Science classrooms. Science Activities, 48, 23-28, https://doi.org/10.1080/00368121.2010.495141

Konishi, H. et al. (2014). Six Principles of Language Development: Implications for Second Language Learners. Developmental Neuropsychology, 39(5), 404-420, https://doi.org/10.1080/87565641.2014.931961

Nguyen Thi Thuy (2018). Promoting problem-solving capability for students via the cognitive activities of thermological knowledge in the junior high school curriculum under the view of Lamap. Doctoral Dissertation, Hanoi National University of Education.

Nguyen Van Gioi (2011). Developing communication skills for students of Ha Giang Ethnic Boarding High School. Master thesis, Thai Nguyen University of Education.

Pham Song Ha (2012). Communication characteristics of Muong ethnic middle school students. Doctoral Dissertation, Graduate Academy of Social Sciences.

Pham Thi Ngoc Thang (2003). Improving the teaching quality of the "electromagnetic induction and alternating current" module in ethnic boarding middle schools through fostering problem-solving capabilities for students. Doctoral Dissertation, Hanoi National University of Education.

Redish, E. \& Kuo, E. (2015). Language of Physics, Language of Math: Disciplinary Culture and Dynamic Epistemology. Science \& Education, 24, 561-590, https://doi.org/10.1007/s11191-015-9749-7

Sutton, C. (1992). Words, science, and learning. Developing science and technology education, Open University Press, Buckingham, Philadelphia, 118.

Sutton, C. (1996). Beliefs about science and beliefs about language. Taylor and Francis Ltd.

Swain, M. (2000). The Output Hypothesis and Beyond: Mediating Acquisition Through Collaborative Dialogue. UK J. Lantolf. Oxford, Sociocultural Theory and Second Language Learning, Oxford University Press, 97-114.

Wellington, J. \& Osborne, J. (2001). Language and literacy in science education. Buckingham: Open University Press.

Zubaidah, S. et al. (2018). Revealing the Relationship between Reading Interest and Critical Thinking Skills through Remap GI and Remap Jigsaw. International Journal of Instruction, 11(2), 41-56, https://oi.org/10.12973/ iji.2018.1124a 